\title{
TOWARDS THE INCREASED UTILIZATION OF GEOTHERMAL ENERGY IN A DISTRICT HEATING NETWORK THROUGH THE USE OF A HEAT STORAGE
}

\author{
Sotirios A. K yriakis $(*)$, Paul L. Y ounger \\ University of Glasgow, School of Engineering, James W att B uilding, Glasgow, G12 8QQ, U nited Kingdom \\ *Corresponding A uthor, E-mail Address: s.kyriakis.1@ research.gla.ac.uk
}

\section{ABSTRACT}

Geothermal energy is a renewable energy source which can provide base-load power supply both for electricity and direct uses, such as space heating. In this paper, district heating systems that are fed by geothermal energy, the so-called geothermal district heating systems, are studied. It is proposed to apply a hot water storage tank in these systems to store hot water in times of low-load and release it to the system during peak load periods in order to minimise the use of peak-up boilers.

For this purpose, two different models are presented and the results are shown for three different cases of heat demand coverage by geothermal energy. First, a model for the sizing of these systems is developed. The main findings highlight the importance of the insulation both for the storage tank and the pipelines of the network. Secondly, a model that studies the daily and the annual operation of the installation is developed followed by an integrated economic and environmental analysis of the proposed solution The results indicate that the proposed solution is financially beneficial compared to the traditional case without use of the storage tank as all the financial indices and cash flows are improved. M ore specifically, the levelised cost of heating decreases by $4.3-14.9 \%$ leading to an increased potential income of $£ 87000-241000$ per year, while the NPV, the IRR and the BCR all increase. Furthermore, the emissions decrease by up to $54.2 \%$ and the load factor increases by up to $3.86 \%$. Therefore, the proposed solution is proved to be beneficial from an economic, environmental and energetic point of view as more geothermal energy is utilised in a more economical way with subsequent environmental benefits.

Keywords: Geothermal energy, District heating, Heat storage, Heat network, Energy utilisation 


\section{INTRODUCTION}

Geothermal energy is the energy contained within Earth's crust and it originates from the processes that occur within Earth and heat conduction taking place to the upper layers [1]. Depending on the temperature of the source, geothermal energy can have many uses, such as electricity production, space heating, aquaculture, agriculture, snow melting, drying, distillation etc. $[2,3]$. Theoretically, temperatures higher than $15^{\circ} \mathrm{C}$ can be utilised through the use of heat pumps [4]. Geothermal energy is a fairly mature technology and is in use in many countries worldwide, with Iceland, Turkey, USA, N ew Zealand, Indonesia and Philippines being the pioneers of geothermal development [5]. It can be stated that geothermal energy is a proven, cheap [6] and renewable energy source [7] that its main advantage compared to the other renewable energy sources is that it can produce base-load energy and does not depend on the weather conditions [8]. On the other hand, geothermal energy depends a lot on the geological conditions onsite and has a high risk of uncertainty in the first levels of exploration. These factors together with the poor financial support have lagged the overall development of geothermal energy [9].

In general, district heating refers to the production of heat in a central plant and its distribution to the end-users via a pipeline network. A district heating network can have many heat sources, such as combined heat and power plants, which is the most common source; conventional boilers; waste incinerators; industrial waste heat source; solar collectors; heat pumps and geothermal energy [10]. The main advantages of district heating compared to local provision of heating in each building are well summarised in $[11,12]$ and include the higher efficiency of the whole procedure, the reduction of emissions, the users. Their heat demand within a day is not constant and a typical profile can be seen in Fig. 1. The published research on 
GDHS with the objective of minimizing the running costs, while in [19] the authors develop a novel control strategy of the system with the objective of maximum exergetic efficiency. In reality, the general approach to cover the heat demand is to fluctuate the geothermal production according to the heat demand till its maximum capacity and when the heat demand is higher than the maximum geothermal production, fossil-fuel peak-up boilers will cover the excess heat demand. In this paper, a different approach for the coverage of the heat demand in proposed. M ore specifically, it is proposed to keep the geothermal production constant each day and add a hot water storage tank, where hot water will be stored in times of low-load, and this stored hot water will be released in the network to cover the peak demands. With this approach, more geothermal energy will be utilised, while less fossil fuel will be used with subsequent environmental benefits. The financial viability of this proposal is crucial and will be studied in detail. Furthermore, it should be made clear that it is not attempted to totally phase out the peak-up boilers, but to minimise their use, as there would be some boilers anyway in the installation for back-up purposes, but also this would lead to an over dimensioning of the whole installation which would turn the investment to unfeasible.

In general, the concept of storing energy in a sensible heat storage has been extensively studied $[20,21,22]$. In the majority of the cases, stratified water tanks are used $[23,24]$. This happens because the inlet temperature of the storage tank is usually variable coming from a CHP plant $[25,26]$ or from solar collectors [27]. On the other hand, the end-users need a specific temperature for their requirements. So, a stratified tank with a high degree of stratification has a maximum possible temperature on its top, which is sent to the users, and a minimum temperature on its bottom which is sent in the production unit $[28,29]$. A novelty of this paper, is that it is proposed not to use a stratified water tank, but a fully mixed storage tank instead. M ore specifically, two storage tanks will be used, one on the supply and one on the return lines of the system that will store hot and cold water, respectively. The hot water storage tank will be studied in detail as the cold water storage tank will be used as a regulator of the flow to the geothermal heat exchanger. For sake of simplicity, in the rest of the text the word tank.

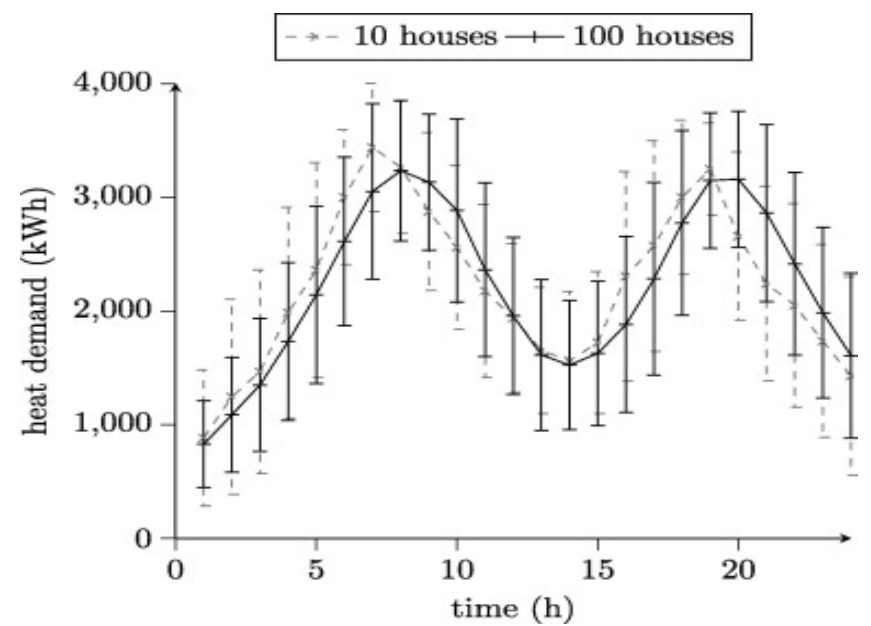


2 The novelties of this paper are the following: The first and most basic novelty is the new way of operation of the GDHS 3 which is proposed and studied. B ased on this direction, two integrated models for the sizing and design of the system as well as for the in-advance knowledge of the operation of the system are built and presented. Finally, as referred previously, the use of a fully mixed tank instead of a stratified tank is another novelty of this paper.

The structure of the paper is as follows: In this section a general introduction in the concept of a GDHS was given; the second section analyses the methodology of the whole approach; the third section provides the results of the analysis together with the discussion and the last section concludes the paper.

\section{METHODOLOGY}

A simplified scheme of the studied installation is shown in Fig.2. The geothermal fluid is pumped in the surface through the production well (P.W.) and its heat is transferred to water through a geothermal heat exchanger (G.H.E.) in order to avoid distribution network and returns to the GHE to be reheated and continue its cycle. Finally, the cooled geothermal water is pumped in the underground through a re-injection well (R.W.).

The study is divided into two main parts. In the first part, an integrated algorithm for the sizing of the installation is built. It should be noted that the installation will operate on daily cycles. In the second part, an algorithm which provides details for the daily operation of the installation is built and then this al gorithm is extended in order to study the annual operation of the installation. By studying the annual operation of the installation, the basic operational costs will be known and these will be used to carry out an economic and environmental analysis of this proposal and a comparison between the proposed and the traditional operation of a GDHS. 


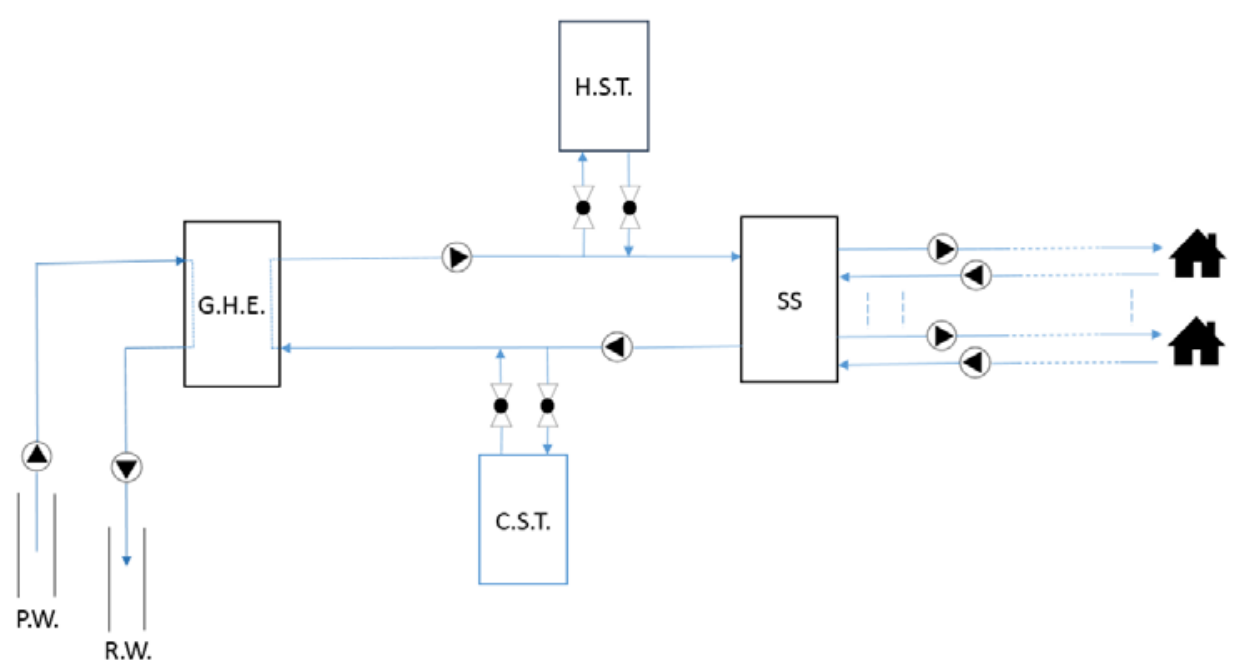

F igure 2. A simplified scheme of the studied installation (G.H.E. = Geothermal Heat Exchanger, H.S.T. = H ot Storage Tank,

\section{C.S.T. = Cold Storage Tank, SS=Substation)}

It was attempted to make the whole model as generic as possible as the design of a GDHS is very case-specific by its own nature. Therefore, many variables of the problem, such as the length of the distribution network, were arbitrary inputs by the author, while in reality, these will be the real inputs by the user.

\subsection{Sizing of the installation}

In the first part of the study, an integrated model for the sizing of the installation was built. The geothermal data, the heat demand data throughout a whole year and the topology of the installation were used as inputs, while the sizing of the installation is the output. The heat demand data should have a fine time discretization for more accurate results. Since the installation operates on daily cycles, a specific day has to be chosen as the design-day on which all the design will be based. In this study, three different cases were studied for which more details will be given on the results section.

Some initial values of the basic parameters of the installation, such as the temperatures across the network, have to be used in the beginning of the calculations. Then, the design-day is selected by the user. In our approach, the geothermal flow rate which will be constant throughout the day, has such a value that the heat demand of this day can be covered by geothermal energy only. Since the geothermal flow rate will be constant, then the mass flow rate on the left of the storage tank (or the mass in each time interval, $M_{t r, G}$ ) will be constant as it will be equal to a specific proportion of the geothermal flow rate which is also an output of this algorithm. In this paper, it is preferred to use the mass throughout a time interval in the calculations, as the heat demand data are known per time interval. The mass on the right of the storage tank $\left(M_{t r, s}\right)$ will, in contrast, be variable throughout the day according to the heat demand.

Based on the values of these masses, the masses of charged, discharged and stored water throughout the design day as well as the volume of the storage tank can be calculated, respectively, as: 
$M_{c h}^{i}=M_{t r, G}-M_{t r, S}^{i}$

$M_{d i s}^{i}=M_{t r, S}^{i}-M_{t r, G}$

$M_{s t}^{i}=M_{c h}^{i}-M_{d i s}^{i}+M_{s t}^{i-1}$

$M_{s t}^{0}=0$

$V_{s t}=\frac{\max \left(M_{s t}^{i}\right)}{\rho} \cdot S F$

2

3

4

5

6

7

$\rho \cdot C p \cdot V_{s t} \cdot \frac{T_{s t}^{i+1}-T_{s t}^{i}}{d t}=\dot{Q}_{+}^{i}-\dot{Q}_{-}^{i}-\dot{Q}_{l o s s}^{i}$

8

9

In the above equation, the left hand side is the accumulation term, balanced by the heat surplus due to charging, the heat

$Q_{+}^{i}=M_{c h}^{i} \cdot C p \cdot\left(T_{s t, i n}-T_{a}\right)$

$Q_{-}^{i}=M_{d i s}^{i} \cdot C p \cdot\left(T_{s t}^{i}-T_{a}\right)$

$Q_{\text {loss }}^{i}=Q_{\text {loss }, \text { top }}^{i}+Q_{\text {loss }, \text { side }}^{i}+Q_{\text {loss }, \text { bot }}^{i}$ 
In Eq. (9), the terms on the right hand side are the heat losses from the top, side and bottom part of the storage tank, respectively. In the top and side parts, the heat losses consist of heat losses due to convection and radiation to the ambient air

3 and conduction through the different layers of the tank, while in the bottom part the heat losses are due to conduction to the underground. For the calculation of the convective heat transfer coefficient in the top part of the tank, the equations for flow parallel to horizontal body are used, while for the side part the equations for flow vertical to a cylindrical body are used. Therefore, the heat losses for each part of the tank are calculated by equations summarised in Table 1 [31].

In the cases of the top and side part of the tank, the calculations depend on the temperature of the stored water each time and the outer surface temperature of the tank, therefore the heat transfer coefficients are assigned with a temporal superscript. In the case of the bottom part, the heat transfer coefficient depends only on the materials, therefore, it is constant all the time. The system of equations (6)-(12) is solved with an iterative method in order to provide the evolution of the temperature of the stored water.

\section{Table 1.}

Sets of equations used for the calculation of the heat losses of the storage tank

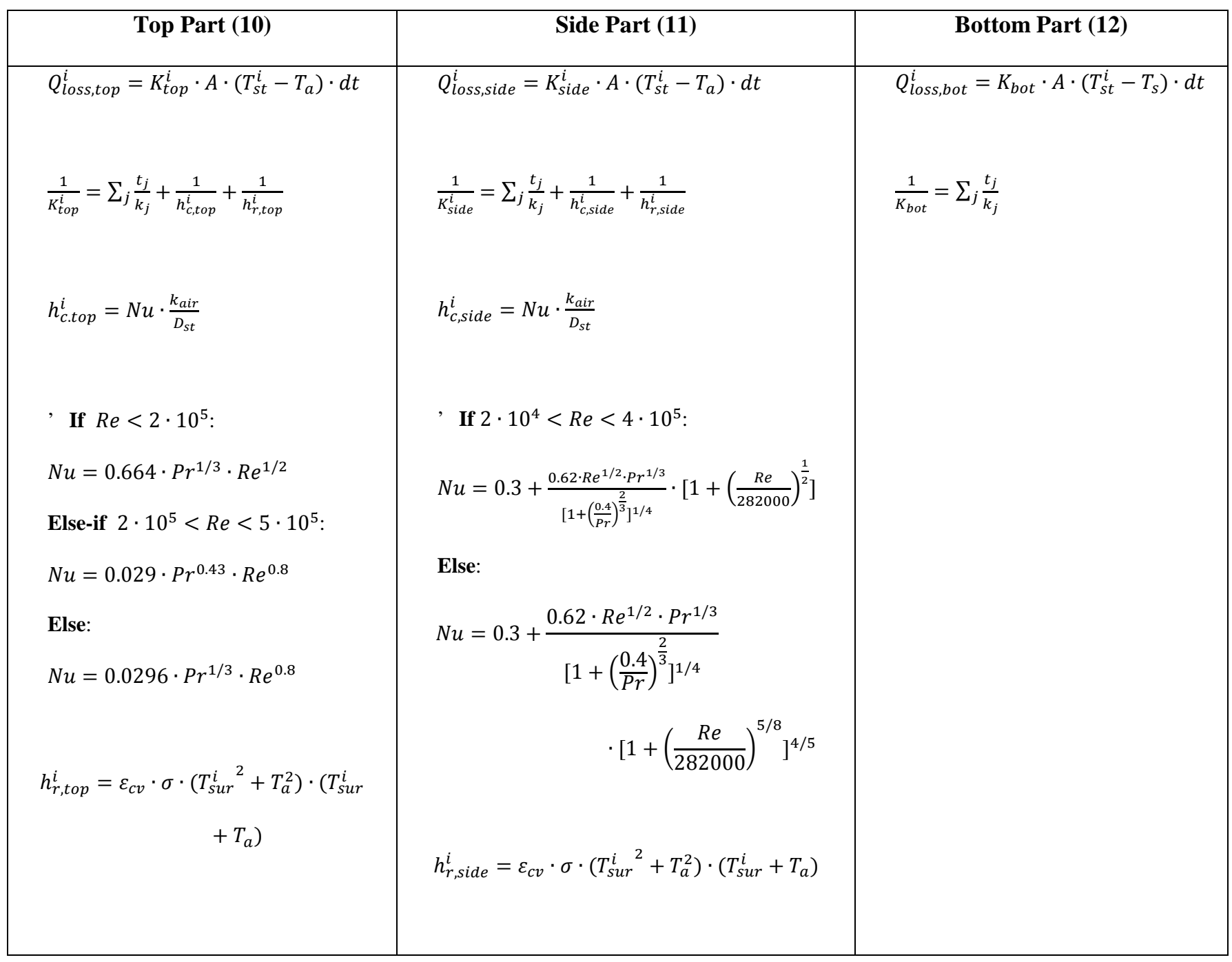


For the sizing of the pipelines of the network, an optimization algorithm is built. The objective function is the minimization of the total cost of the pipelines, which includes the capital cost, the cost of electricity used by the pumps to overcome the friction losses and the cost of the heat losses. The latter is not a direct cost, but an indirect monetary loss, so it is also taken into account in the total cost. Other possible costs are not taken into account since these are considered equal for each case. The optimization parameters are the external diameter of the pipeline and the thickness of the insulation. Standardised values of external diameters according to EN 10220 [32] were used.

The cost of the heat losses is calculated by multiplying the heat losses by a unit price of heating. For the calculation of the heat losses, a system of double underground pre-insulated pipes was used (Fig.3). The pipelines are discretized in space and for each pair of discretized pipes the average values for the supply and return temperatures are considered. The equations summarised in [33] are then used for the calculation of the heat losses. It is found that an optimum space discretization of the pipelines is $10 \mathrm{~m}$.

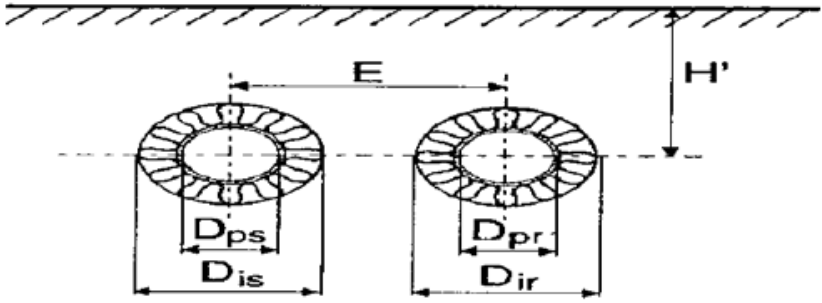

$\dot{P}_{p}=\frac{\rho \cdot g \cdot\left(\delta h_{l}+\delta h_{\text {elev }}\right) \cdot \dot{V}}{\eta_{p}}$

$C_{e l, t o t}=\dot{P}_{p} \cdot(A O H) \cdot C_{e l, u}$

The friction losses in Eq. (13) are calculated by the Darcy-W eisbach equation. Since the pipelines are sized and their heat losses are known, then the temperatures across the network can be calculated. So, all the necessary data for the sizing of the installation are known. Finally, the efficiency of the installation for the design day can be calculated as:

$\eta_{G, D}=\frac{D H D_{D}}{\dot{m}_{G, D} \cdot C p \cdot \mathrm{d} T_{G, D} \cdot 86400}$ 
Since the initial assumptions are made, the equations (1)-(15) are used for the sizing of the installation. Through these equations, new values of the initial assumptions are calculated. Therefore, an iterative process will be followed till the convergence of the problem.

\subsection{Operational and economic analysis}

6

$$
\dot{m}_{G}=\frac{\frac{D H D}{86400 \cdot \eta_{G}}+\frac{M_{s t}^{0} \cdot C p \cdot\left(T_{s t}^{0}-T_{a}\right)}{86400}}{C p \cdot \mathrm{d} T_{G}}
$$
equation:

The second part of the study is divided in three different sub-parts. In the first two parts, the operation of the installation is studied over a random day and over a year, respectively, while in the third part an integrated economic and environmental analysis of the investment together with a comparison with the traditional case are carried out.

Firstly, a robust model is built for the study of the operation of the installation in a random day. M ore specifically, in this model the inputs are the outputs of the first part of the study, i.e. the sizing of the installation, and the heat demand of a random day. In other words, the sizing of the installation is now known and this algorithm will provide the operational strategy of the installation for a day with a known or predicted heat demand under the operation proposed in this paper. By operational strategy, the author defines the complete knowledge of the operation of the installation, for example, when and by how much should the storage tank be charged or discharged, when and by how much should the peak-up boilers be used etc. Theoretically, this algorithm would be quite useful for the operators of the installation, as they would know in advance how they should operate the installation the coming day that has a known, or predicted in reality, heat demand.

Initially, the necessary geothermal flow rate can be calculated by the following properly re-arranged energy conservation

In the above equation, $D H D$ is the daily heat demand, while the factors with the superscript 0 denote values of the first time interval of the studied day, which in reality would be the values from the last time interval of the previous day. Therefore, these specific values will be known. Actually, these factors take into account any remaining energy from the stored water of the previous day. Obviously, in this case the initial mass of stored water is not necessarily zero as in section 2.1, but is a known value from the previous day. Furthermore, any possible mass of stored water in the end of the day is not taken into account now, since the masses are not known yet. At the moment, it is also considered that the peak-up boilers will not be used throughout the day, while the total efficiency of the installation $\left(\eta_{t o t}\right)$ and the temperature drop of the geothermal fluid $\left(d T_{G}\right)$ are initial estimations. Later on, all these assumptions will be checked and renewed through an iterative process. 
Since the geothermal flow rate is known, then the same process as in section 2.1 can be followed for each time interval to calculate all the masses and the temperatures across the network. The only difference, as al ready said, is that the initial mass of stored water might not be zero as in Eq. (4). Furthermore, in some cases the mass of stored water within the day will be zero, so the mass of discharged water will not be calculated by Eq. (2), but will also be equal to zero. In order to identify if the peak-up boilers should be used, the following loop is applied:

, For each time interval i:

If $M=M_{s t}^{i}+M_{c h}^{i}-M_{d i s}^{i}<0$

Then $M_{b}^{i}=a b s(M)$

Else $M_{b}^{i}=0$

7

In the above loop $M_{b}^{i}$ is the mass of water that should be provided to the network by the boiler. Therefore, for a specific boiler and a known temperature increase in the boiler's water, the mass of fuel provided to the boiler will be known. Since all the masses and temperatures of the network are known across the day, a renewed value of the temperature drop of the geothermal fluid can be calculated. If the peak-up boiler has been used, the part of the daily heat demand that is covered by geothermal energy $\left(D H D_{G}\right)$ can be easily calculated.

It is reminded that Eq. (16) refers in the geothermal part of the installation, but since it is not known in advance if the peakup boilers will be used, it is written in more general terms. Finally, any possible mass of stored water in the end of the day has to be taken into account now. Therefore, a renewed value of the efficiency of the geothermal part of the installation can be calculated as:

$\eta_{G}=\frac{D H D_{G}+M_{s t}^{N} \cdot C p \cdot\left(T_{s t}^{N}-T_{a}\right)}{86400 \cdot\left[\dot{m}_{G} \cdot C p \cdot \Delta T_{G}^{\text {new }}+M_{s t}^{0} \cdot C p \cdot\left(T_{s t}^{0}-T_{a}\right)\right]}$

Then, a renewed value of the geothermal flow rate can be calculated by Eq. (16) and the whole process is repeated till convergence of the problem. The output of this model is the operational strategy of the installation as well as the total amount of fuel used by the peak-up boilers and the total amount of electricity used by the pumps throughout the day.

In the second sub-part, the above model is extended for the study of the operation of the installation over a whole year. The extended model will actually repeat the previous process for each day of the year serially just by using the data of the last time interval of the previous day as the data of the first time interval of the next day. The outputs of this model will be the same as those of the previous model, but in this case, the outputs of interest are the total amount of fuel and the total electricity used throughout the year. These comprise the main operational costs of the installation and together with some 
assumptions about the other operational and maintenance costs, the total annual running costs of the installation will be known.

The total annual running costs are used together with the capital costs in the third and last sub-part for an integrated economic analysis of the investment. A comparison will be made with the traditional approach in order to examine if the proposed solution is feasible. Furthermore, the total amount of fuel per year will be used to carry out an environmental analysis of the installation.

The capital cost of the installation is calculated by the following equation:

$$
L C H=\frac{C C \cdot C R F+O C}{A H D}
$$


$C R F=\frac{i r}{1-(1+i r)^{-I P}}$

2

3

The other financial indices used for the comparison of the two cases are the net present value (NPV), the internal rate of return (IRR) and the benefits-to-cost ratio (BCR) [35]. In the following, few details will be given on the calculation of the inflows and outflows of the investment, as these are necessary for the calculation of the financial indices and for the cash flow graphs. The inflow of the investment consists of the following three parts:

- A fixed cost per day which guarantees a certain income and is used for the repayment of the capital cost. It is fixed in such a value so that the initial capital cost is repaid within 10 years.

- A variable cost which depicts the real consumption of energy and is fixed in $£ 0.02 / \mathrm{kWh}$ of heat provided.

- A financial incentive recently established in UK, the so-called RHI (Renewable Heat Incentive), which provides $£ 0.05 / \mathrm{kWh}$ of renewable heat provided. This value increases by $2.5 \%$ each year and the incentive is provided for the first 20 years of operation.

The latter might not always be the case, but in this study the calculations of the economic analysis will be made for the cases that the $\mathrm{RHI}$ is taken and not taken into account in order to identify the influence of a financial subsidy in a renewable project. The outflows of the investment consist of the capital and operational costs. The main capital cost shown in the results are upfront costs, while it is assumed that the boilers will be replaced after 20 years of operation and the heat exchangers and the pumps will be replaced after 15 years. Concerning the operational costs, their average annual increase was calculated for the last 10 years, and it is assumed that their annual increase in the future will be equal to this value. Finally, the discount rate, the interest rate and the investment period were assumed to be $5 \%, 6 \%$ and 30 years, respectively.

Furthermore, since the total amount of fuel used per year is known, the emissions can be easily calculated through the stoichiometry of the fuel and charts of combustion. In this study, only the local emissions will be calculated, as it is very difficult to quantify the emissions during the construction of a GDHS. The only published value of the levelised life-cycle emissions of a geothermal heat only project is in [36] and equals to $4 \mathrm{~g} \mathrm{CO}_{2} / \mathrm{kWh}$. Furthermore, in this study the comparison between the two cases is carried out and not with other alternative energy sources, and therefore, the comparison of the local emissions is considered to be sufficient for that purpose. Finally, the load factor is calculated as the ratio of the average geothermal flow rate throughout the year divided by the maximum available geothermal flow rate. Any possible out of operation hours are not taken into account.

\section{RESULTS AND DISCUSSION}




\subsection{Sizing of the installation}

2

3

The heat demand data used as a test case were provided by the Estates and B uildings Office of the University of Glasgow and refer to several buildings managed by the specific office. The annual heat demand is around 38500M Wh with an average and peak demand of 4.4 and $14 \mathrm{M} \mathrm{W}$, respectively, while the time discretization of the data is 30 minutes. A plot of the data can be seen in Fig 4. In this figure, in can be seen that the heat demand is very peaky and it is made obvious that it would not be viable to size the geothermal installation to cover all the heat demand. The other necessary data are case-specific for each problem. In reality, these will be the inputs by the user of the model. In our case, these are chosen arbitrarily by the authors. A list of the basic inputs of the problem can be seen in Table 2.

As al ready mentioned, a specific day has to be chosen by the user as the design-day. In our case, three different days are chosen and studied in order to study the effect of the heat demand coverage by geothermal energy on the viability of the project. M ore specifically, the chosen days are those that their daily heat demand is equal to the $25^{\text {th }}-, 50^{\text {th }}$ - and $75^{\text {th }}$-centile of the daily heat demands of the whole year. For sake of simplicity, these cases will be called $25-C, 50-C$ and $75-C$ in the rest of the paper, respectively. So, three different and very discrete cases which affect primarily the sizing of the installation will be studied. Their effect on the economics of the installation will be studied in the next section.

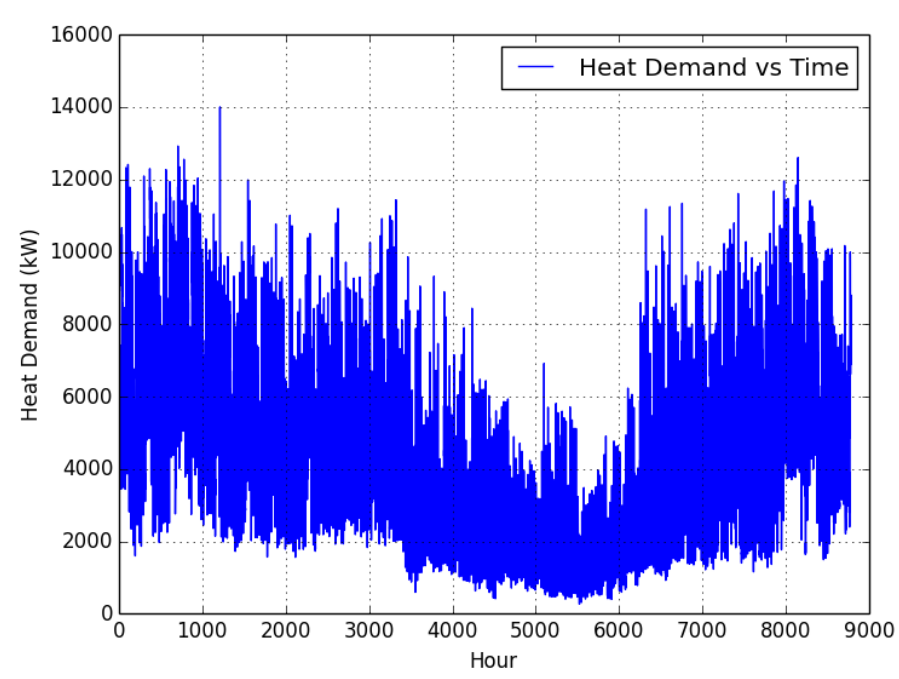

\section{Table 2}

M ain input data

\begin{tabular}{|l|l|}
\hline Data & Value \\
\hline & \\
\hline
\end{tabular}




\begin{tabular}{|l|l|}
\hline M ass flow rate of each well $(\mathrm{kg} / \mathrm{s})$ & 20 \\
\hline Temperature of the geothermal fluid $(\mathrm{K})$ & 353.15 \\
\hline L ength of transmission pipeline $(\mathrm{m})$ & 1500 \\
\hline M inimum temperature difference on the hot side of the G.H.E. & 5 \\
\hline K $)$ & \\
\hline A mbient design temperature (K) & 283.15 \\
\hline
\end{tabular}

1

As already mentioned, a specific day has to be chosen by the user as the design-day. In our case, three different days are chosen and studied in order to study the effect of the heat demand coverage by geothermal energy on the viability of the project. M ore specifically, the chosen days are those that their daily heat demand is equal to the $25^{\text {th }}$-, $50^{\text {th }}$ - and $75^{\text {th }}$-centile of the daily heat demands of the whole year. For sake of simplicity, these cases will be called $25-C, 50-C$ and $75-C$ in the rest of the paper, respectively. So, three different and very discrete cases which affect primarily the sizing of the installation will be studied. Their effect on the economics of the installation will be studied in the next section.

The main results are shown in Table 3 and refer to the design-day for each case. As can be seen in this Table, the temperature drop of the geothermal fluid is almost the same in each case and is very close to $30 \mathrm{~K}$ degrees. Therefore, the geothermal power increases al most proportionally with the number of wells. The efficiency of the installation increases as the coverage by geothermal energy increases and its value ranges roughly between $86.88-87.61 \%$.

Table 3

M ain results of the sizing of the installation

\begin{tabular}{|l|c|c|c|}
\hline Case & 25-C & 50-C & 75-C \\
\hline No of wells & 1 & 2 & 3 \\
\hline$\dot{\boldsymbol{m}}_{\boldsymbol{G}}(\boldsymbol{k g} / \boldsymbol{s})$ & 20 & 40 & 60 \\
\hline$\dot{\boldsymbol{m}}_{\boldsymbol{t r}, \boldsymbol{S}}(\boldsymbol{k g} / \boldsymbol{s})$ & 29.87 & 60.10 & 92.26 \\
\hline$\dot{\boldsymbol{Q}}_{\boldsymbol{G}}(\boldsymbol{k W})$ & 2520.6 & 5006.5 & 7502.4 \\
\hline $\boldsymbol{d T}_{\boldsymbol{G}}(\boldsymbol{K})$ & 30.079 & 29.872 & 29.843 \\
\hline $\boldsymbol{\eta}_{\boldsymbol{t o t}}(\%)$ & 86.886 & 87.431 & 87.610 \\
\hline $\boldsymbol{V}_{\boldsymbol{s t}}\left(\boldsymbol{m}^{\mathbf{3}}\right)$ & 341.93 & 592.34 & 1132.30 \\
\hline $\boldsymbol{D}_{\boldsymbol{s t}}, \boldsymbol{H}_{\boldsymbol{s t}}(\boldsymbol{m})$ & 7.579 & 9.102 & 11.297 \\
\hline
\end{tabular}

The volume of the storage tank increases with the increase of the coverage by geothermal energy, but not proportionally. This happens because the mass of stored water, and volume of storage tank subsequently, depends strongly of the fluctuation 
1 of the heat demand within the specific chosen day. Two days might have the same daily heat demand, but the fluctuation 2 within the day can be very different. Furthermore, from a thermo-economic perspective it is found that the optimum height3 to-diameter ratio of the storage tank is equal to 1 . Finally, it can be seen that the ratio $\dot{m}_{t r, s} / \dot{m}_{G}$ is almost the same in the three 4 cases, almost equal to 1.5 , but not exactly the same as it is a value provided by the algorithm, as mentioned earlier. This 5 finding also agrees with the literature [37] that states that this value has to be higher than 1.

In Figs. 5a-5c, the mass of stored water and in Figs. $6 a-6 c$ its temperature evolution throughout the day are shown, respectively. The different values of the stored water in each case reflect the difference in the mass flow rates and in the volume of the storage tank as shown in Table 3. It can be seen that the graphs follow the same trend in each case. The higher temperature decreases occur during the first and, mainly, the last hours of the day where the storage tank is almost empty. The rest of the day the heat losses of the tank are almost negligible. The only exception is the graph that depicts the temperature evolution of stored water in the smaller sizing (Fig. 6a), where especially in the first hours there is a much steeper decrease in the temperature. This happens because there is no stored water for many hours and the mathematical model shows some instability. The Figs. $6 a-6 \mathrm{c}$ highlight the effect of the insulation, which in our case is $20 \mathrm{~cm}$, showing that the heat losses in a well-insulated tank can be minimized. The thickness of the insulation comes also in agreement with publishes values [38].

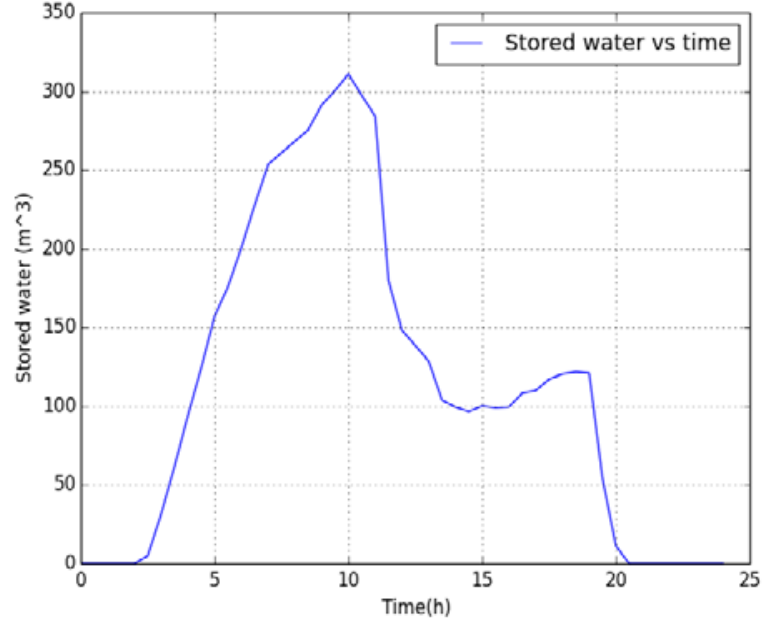

Figure 5a. Mass of stored water over time (25-C)

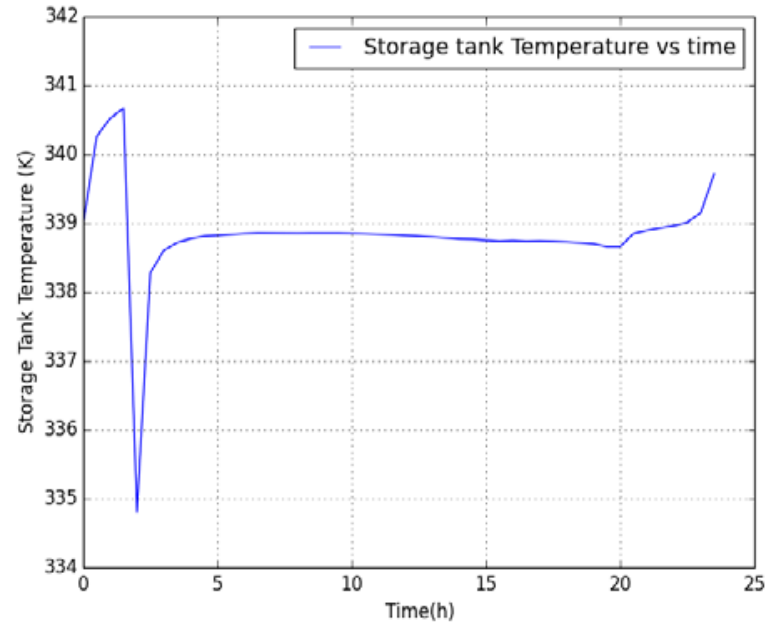

F igure 6a. Temperature evolution of stored water over time (25-C) 


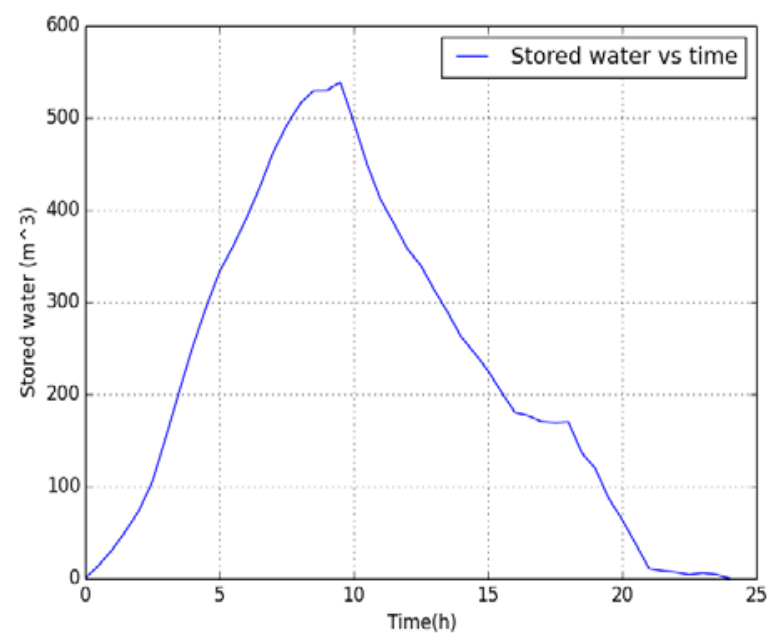

F igure 5 b. M ass of stored water over time (50-C)

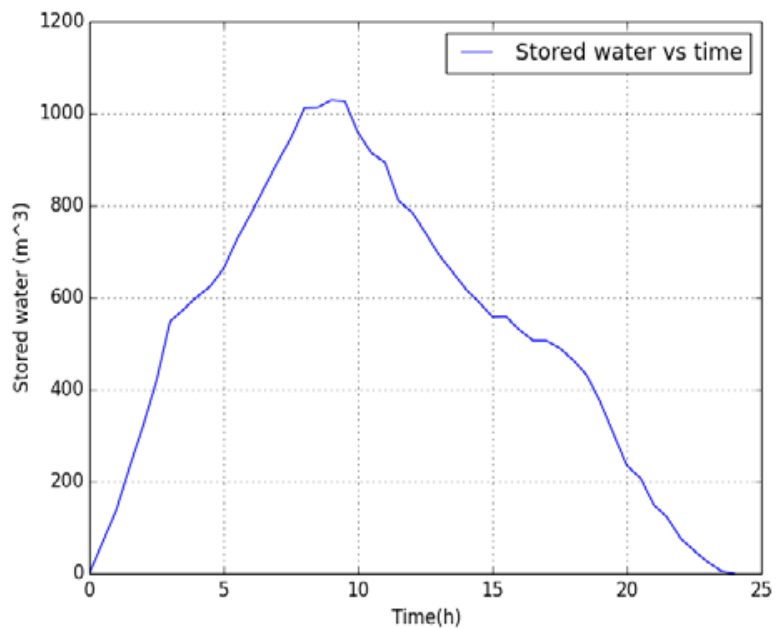

F igure $5 \mathbf{c}$. M ass of stored water over time (75-C)

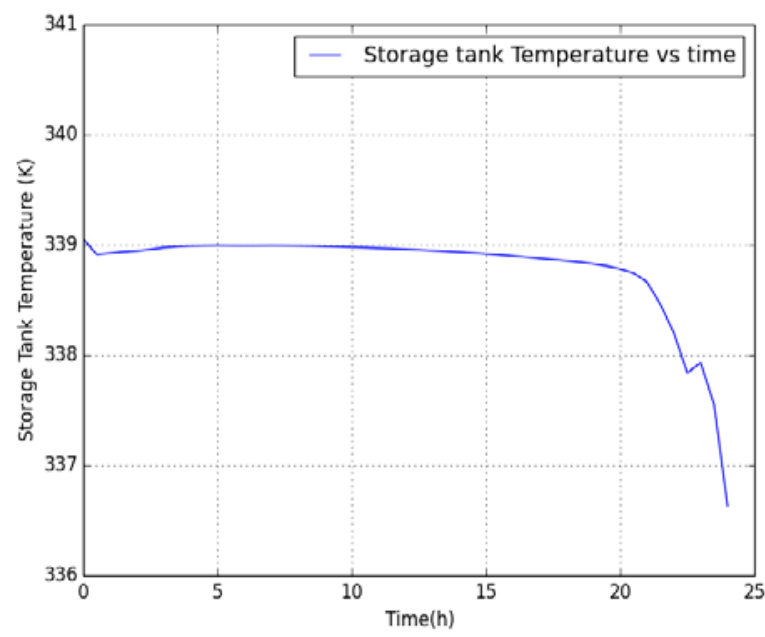

F igure $\mathbf{6 b}$. Temperature evolution of stored water over time $(50-C)$

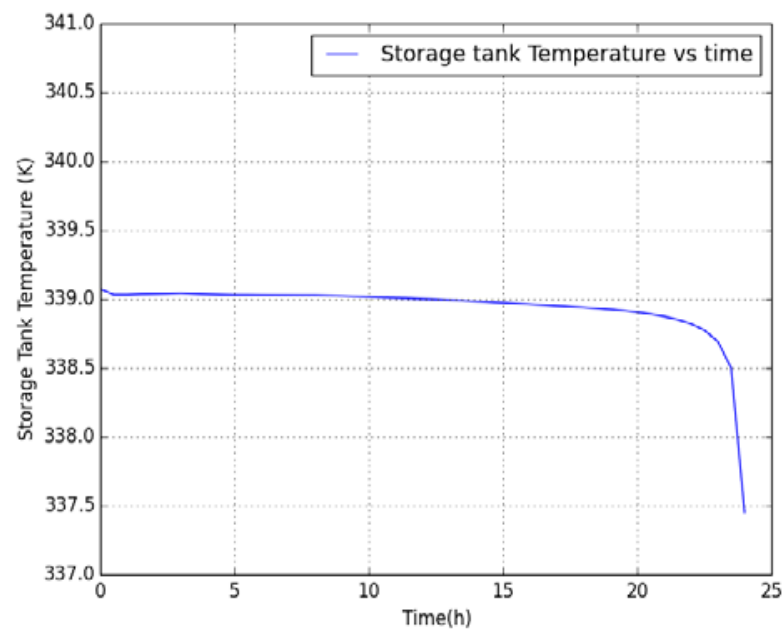

F igure $\mathbf{6 c}$. Temperature evolution of stored water over time $(75-C)$
1

In Table 4, the design temperatures of the transmission network are shown. Since the length of the transmission network is $1500 \mathrm{~m}$, the temperature drop in the pipelines is in the range of $0.028-0.121 \mathrm{~K} / \mathrm{km}$. This value is somewhat lower than those presented in the literature, e.g. in [15]. This happens because in the developed algorithm, the heat losses of the pipelines are taken into account and a quite thick insulation is used. This can also be seen in Table 5 where the dimensions of the pipelines of the transmission network are shown. Probably, in reality the heat losses were not taken into account as much as they should. Furthermore, the fact that these are simulation results and not real data might be partly a reason for this disagreement. 
1 Although the results are quite lower than other published ones, it can be seen that there are some important differences

2 between them. This happens because the optimization algorithm does not take into account, on the other hand, only the heat

3 losses, but also the capital and running costs, so it seems that for different flow rates the optimum cases are relatively

4 different. But, in any case, the heat losses are quite small highlighting this way the effect of the insulation and the advantages

5 of this algorithm. Finally, it was shown that the heat losses of the pipelines are minimised if the supply and the return

6 pipelines are laid as close to each other as possible.

7

8

9

10

11

Table 4

Design temperatures of the transmission network ( $\mathrm{S}=$ Supply, $\mathrm{R}=$ Return, Temperatures in $\mathrm{K}$ )

\begin{tabular}{|l|c|c|c|}
\hline Case & 25-C & 50-C & 75-C \\
\hline S-Inlet & 339.150 & 339.150 & 339.150 \\
\hline S-O utlet & 338.968 & 339.043 & 339.066 \\
\hline R-Inlet & 320.013 & 320.199 & 320.263 \\
\hline R-O utlet & 319.909 & 320.141 & 320.221 \\
\hline
\end{tabular}

Table 5

Optimum dimensions of the transmission network $(\mathrm{cm})$

\begin{tabular}{|c|l|l|l|}
\hline Case & 25-C & $\mathbf{5 0 - C}$ & $\mathbf{7 5 - C}$ \\
\hline & & & \\
\hline $\boldsymbol{D}_{\boldsymbol{i}}$ & 21.45 & 26.78 & 34.92 \\
\hline $\boldsymbol{D}_{\boldsymbol{o}}$ & 21.91 & 27.30 & 35.56 \\
\hline $\boldsymbol{t}_{\text {ins }}$ & 20 & 20 & 21 \\
\hline
\end{tabular}


The basic results of the economic and environmental analysis of the investment together with a comparison with the traditional case of not using a storage tank will be shown in this section. Furthermore, the basic results from the annual operation of the installation that are used in the economic analysis will also be shown. The sizing of the installation shown in section 3.1 for each case, together with the annual heat demand, were used in the algorithm of the annual operation of the installation to calculate the basic operational costs.

In Table 6, the capital and operational costs for each case with and without the storage tank are shown and refer to the first year of operation. First, it can be seen that the capital cost of the proposed case is lower than the traditional case for each sizing of the installation, although the proposed case has the extra cost of the storage tank. This happens because in the case without the storage tank, bigger peak-up boilers are needed to cover the peak demands and this difference in the size of the boilers is big enough to cover the cost of the storage tank. It can also be seen that the capital cost increases as the sizing of the installation increases, which is totally expected as more wells are needed.

Concerning the operational cost of fuel, it is seen that for each case of sizing the cost of fuel is smaller in the case with the higher fraction of the heat demand is covered by geothermal energy. Additionally, it is seen that when the sizing of the installation increases, the cost of fuel decreases. This is also expected because by increasing the sizing of the installation, and more specifically of the geothermal part, more geothermal energy will be produced and will cover heat demand, which subsequently will decrease the use of fuel. By observing this data, it is observed that the biggest decrease of fuel cost when using the tank is in the middle case of sizing $(50-\mathrm{C})$, which means that in this case the storage tank is utilised in the optimum way. In the smaller case of sizing $(25-\mathrm{C})$, most of the geothermal energy will be sent directly to the consumption, so the rest of the heat demand that would be covered by the boilers will not be that different between the proposed and the studied case. Therefore, the difference in the cost of fuel is relatively small. On the other hand, in the biggest sizing of the installation (75C), a very big part of the load is covered by geothermal energy in any case and the fuel that needs to be used is quite small. Although the cost of fuel if the storage tank is used is the half compared to the traditional case, it can be seen that this cost is quite small anyway.

The operational cost of the pumps is almost the same between the case with and without the storage tank. This means that the pumps consume almost the same amount of electricity no matter if the storage tank is used or not. On the other hand, as the sizing of the installation increases, the operational cost of the pumps decreases. This is justified by the fact that as the sizing increases, the size of the pipelines also increases (see Table 5) and the pumping costs, have a decreasing trend. Finally, the total operational cost is always smaller when the storage tank is used, and decreases when the sizing of the installation increases. This is justified by the previous observations. So, both the capital and the operational costs are smaller when the 
1 storage tank is used, while the first one increases and the second one decreases with the increase of the sizing of the

2 installation.

4 Table 6

5 Capital and operational costs of all the cases ( $\mathrm{W} \mathrm{i}=\mathrm{W}$ ith the storage tank, $\mathrm{Wo}=\mathrm{W}$ ithout the storage tank, Costs in $\mathrm{f}$ )

$$
C C_{d r}
$$

$$
{ }^{C C_{H . S . T .}}
$$$$
C C_{m p}
$$

$C C_{b}$

$$
\text { CC } C_{\text {tot }}
$$

$o c_{f}$

$o c_{p}$

$O C_{\text {tot }}$

\begin{tabular}{|c|c|c|c|c|c|c|}
\hline \multicolumn{7}{|c|}{ RHI included } \\
\hline & $L C H(£ / k W h)$ & $N P V\left(£ \cdot 10^{6}\right)$ & $\operatorname{IRR}(\%)$ & $B C R(-)$ & $\begin{array}{l}\text { A nnual } \mathrm{CO}_{2} \text { emissions } \\
(\mathrm{kg})\end{array}$ & Load factor (\%) \\
\hline $25-C-W i$ & 0.04988 & $<0$ & $<0$ & $<0$ & 5236608 & 96.694 \\
\hline 25-C-Wo & 0.05214 & $<0$ & $<0$ & $<0$ & 5478858 & 93.882 \\
\hline $50-C-W i$ & 0.03574 & 60.478 & 29.10 & 5.689 & 1959106 & 80.631 \\
\hline $50-\mathrm{C}-\mathrm{W} 0$ & 0.04202 & 48.144 & 24.83 & 4.327 & 2757729 & 80.267 \\
\hline 75-C-Wi & 0.03162 & 94.044 & 32.55 & 7.434 & 309000 & 64.478 \\
\hline 75-C-W o & 0.03581 & 89.334 & 30.30 & 6.555 & 675000 & 62.080 \\
\hline & & & RHI no & ncluded & & \\
\hline
\end{tabular}

\begin{tabular}{|l|c|c|c|c|c|c|c|c|}
\hline 25-C Wi & 3500000 & 35478 & 1636274 & 3101400 & 10012558 & 763682 & 106407 & 1043876 \\
\hline $\mathbf{2 5 - C ~ W ~ o ~}$ & 3500000 & 0 & 1636274 & 3532800 & 10386087 & 799011 & 106302 & 1082975 \\
\hline $\mathbf{5 0 - C ~ W i}$ & 5000000 & 53644 & 1737049 & 2521400 & 11069181 & 285707 & 41000 & 448052 \\
\hline $\mathbf{5 0 - C ~ W ~ 0 ~}$ & 5000000 & 0 & 1737049 & 3512000 & 11966065 & 402109 & 40991 & 577217 \\
\hline & & & & & & & & \\
\hline $\mathbf{7 5 - C ~ W i}$ & 6500000 & 90221 & 1860405 & 2530400 & 12776285 & 48771 & 20360 & 164076 \\
\hline $\mathbf{7 5 - C ~ W o ~}$ & 6500000 & 0 & 1860405 & 3504400 & 13581822 & 98489 & 20357 & 219652 \\
\hline Table 7 & & & & & & & & \\
\hline
\end{tabular}

$7 \quad M$ ain results of the financial and environmental analysis 


\begin{tabular}{|l|l|l|l|l|l|l|}
\hline $\mathbf{2 5}-\mathbf{C}-\mathbf{W i}$ & 0.04988 & $<0$ & $<0$ & $<0$ & 5236608 & 96.694 \\
\hline $\mathbf{2 5 - C - W ~ o ~}$ & 0.05214 & $<0$ & $<0$ & $<0$ & 5478858 & 93.882 \\
\hline $\mathbf{5 0 - C - W i}$ & 0.03574 & 36.371 & 16.90 & 3.820 & 1959106 & 80.631 \\
\hline $\mathbf{5 0 - C - W ~ o ~}$ & 0.04202 & 26.592 & 13.68 & 2.838 & 2757729 & 80.267 \\
\hline & & & & & & 64.478 \\
\hline $\mathbf{7 5 - C - W i}$ & 0.03162 & 64.567 & 20.10 & 5.425 & 309000 & 62.080 \\
\hline 75-C-W o & 0.03581 & 61.117 & 18.30 & 4.800 & 675000 & \\
\hline
\end{tabular}

1

In Table 7, the main results of the economic and environmental analysis are shown for all the three cases of sizing with and without the storage tank as well as when the RHI subsidy is taken into account or not. The levelised cost of heating, the annual $\mathrm{CO}_{2}$ emissions and the load factor do not depend on the $\mathrm{RHI}$, so their values are the same either if it is taken into account or not. Furthermore, it can be seen that in every case the financial factors indicate that the proposed case is financially favourable compared to the traditional case. M ore specifically, the levelised cost of heating decreases, while the NPV, IRR and BCR all increase. It can also be seen that the biggest change in the financial favourability of the investment occurs in the middle sizing case where, as al ready referred, the storage impacts most.

This difference in the levelised cost of heating denotes an increased potential income between 87000 and $241000 \mathrm{f}$ depending on the case if the heat storage is used. A very important finding from Table 7 is that the viability of the investment increases when the sizing of the installation increases. So, if there is no restricting factor such as non-favourable geological conditions, the geothermal installation should be sized on the maximum sizing, even if the storage impacts most the medium sizing of the installation.

Furthermore, it can be seen that the investment of the minimum sizing of the installation is not viable in any case although the use of the heat store is beneficial. This happens because the operational costs are very high compared to the inflows of the investment. In order to overcome this problem a solution would be to increase the variable cost of heating $\left(2^{\text {nd }}\right.$ part of the income), so that the inflow of the investment will increase. But, in general, sizing the installation to cover a small part of the load by geothermal energy should be avoided.

A nother crucial finding from Table 7, is the tremendous assistance of a financial subsidy on a renewable project. As can be seen in the results, all the financial indices increase by $50 \%$ or more when the $\mathrm{RHI}$ is taken into account. This can also be made clear in Figs. 7a, 7b, 8a and 8b where the cash flow charts of the middle and high sizing of the installation are shown for the cases that the $\mathrm{RHI}$ is taken and is not taken into account, respectively. As can be seen in these graphs, the effect of the $\mathrm{RHI}$ is very important and decreases the payback period of the investment. It should be noted that the change in the slope in 
1 these graphs in the 20 years of the investment is because the $\mathrm{RHI}$ is not provided after this period of time, so the income 2 consists only of the first two parts after the $20^{\text {th }}$ year of operation. It can also be made clear that the effect of the heat storage 3 is much more important in the case of the middle sizing of the installation compared to the case of the high sizing.

Concerning the emissions of the installation, it can be seen that the emissions of $\mathrm{CO}_{2}$ decrease if the heat storage is used 5 for any case of sizing of the installation. This is totally expected, since the emissions are directly proportional to the amount 6 of fuel used. The relative decrease of the emissions in the $25-C$ is small since, as already mentioned, almost all the geothermal production is sent directly to the heat load and, therefore, the change in the operation of the peak-up boilers is not tremendous. On the other hand, the highest absolute decrease of emissions is for the 50-C case where the impact of the heat storage is the maximum. It can also be seen that the emissions decrease as the sizing of the installation increases. Since the sizing of the installation increases, more geothermal energy and less fuel are used, so the emissions will decrease. This findings and trends are in agreement with the results shown on Table 6 about the operational cost of fuel.

Finally, in Table 7 it can be seen that the load factor of the geothermal part of the installation increases when the heat store is used. This means that the geothermal part of the installation operates in a higher average flow rate increasing this way the utilisation of geothermal energy. On the other hand, the load factor decreases as the sizing of the installation increases. This happens because as the sizing of the installation increases, the potential geothermal production increases, so there can be many times of the year that the heat demand can be covered just by a part of the geothermal production. When the sizing of the installation is the smallest one, the potential geothermal production is low, so almost all the geothermal production is sent directly to the heat demand. For example, in our case, in the smallest sizing of the installation the load factor is $96.694 \%$ when the heat store is used, which means that the geothermal installation is working very close to its full capacity all the year.

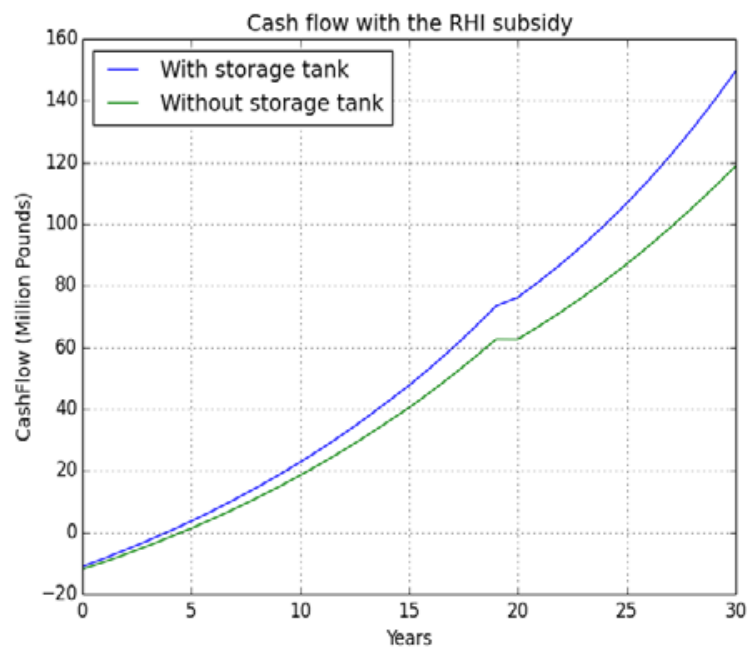

Figure 7a. Cash flow with the RHI subsidy (50-C)

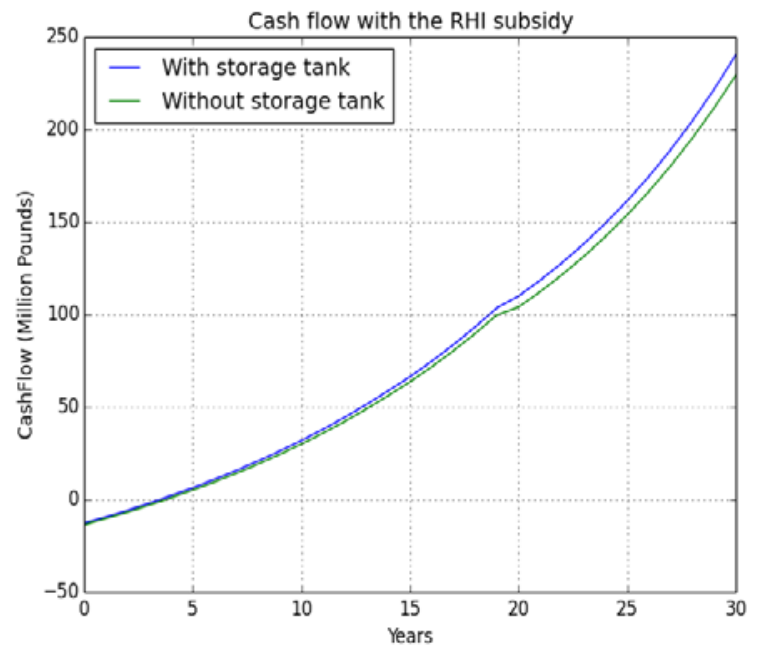

F igure 8a. Cash flow with the RHI subsidy $(75-\mathrm{C})$ 


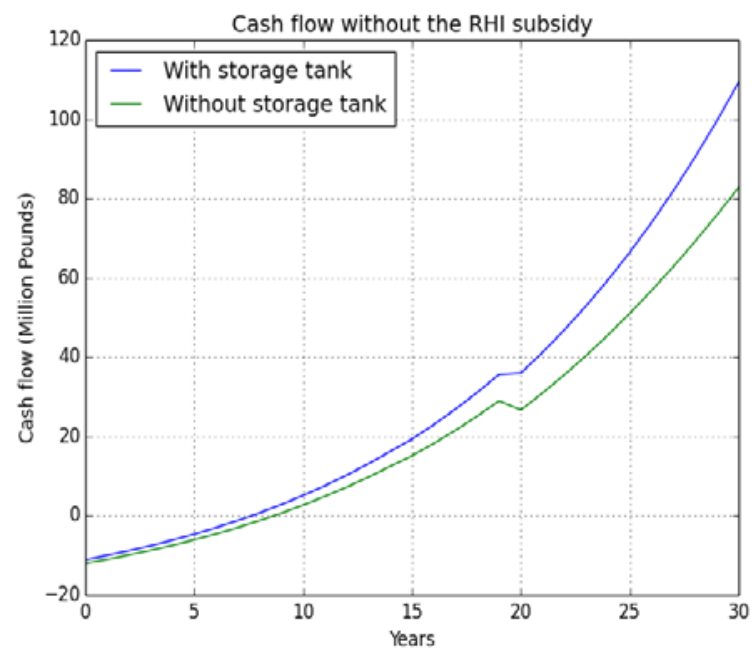

Figure 7b. Cash flow without the RHI subsidy (50-C)

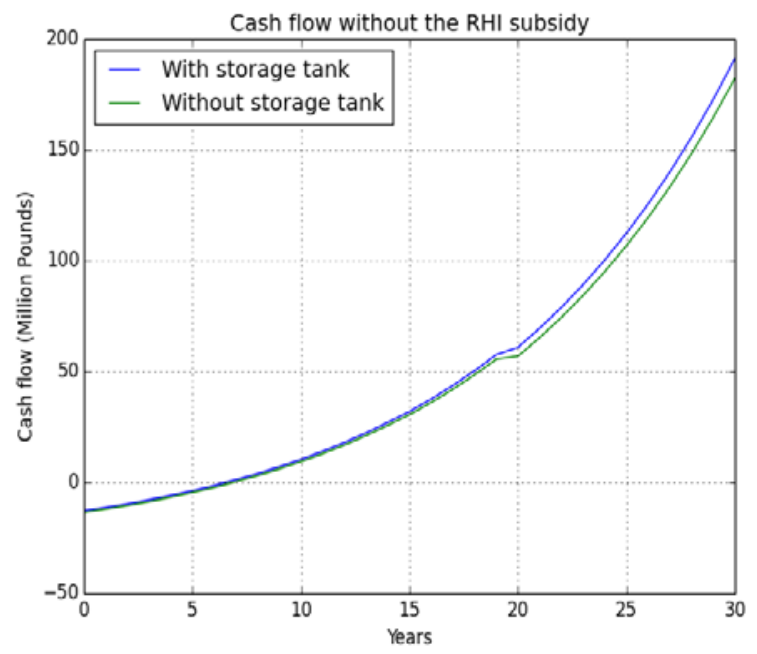

Figure $\mathbf{8 b}$. Cash flow without the RHI subsidy (75-C)
1

\section{CONCLUSION}

The effect of applying a hot water storage tank to cover a part of the peak-load in a GDHS under a different control strategy has been studied in this paper. Typically, in these systems the geothermal flow rate is variable within the day according to the heat demand and the peak demands are covered by boilers. It is proposed to keep the geothermal flow rate constant throughout the day and store hot water in times of low-load and release it in peak demand times. First, an algorithm for the sizing of the installation was developed and the outcome of this algorithm was used as input in the second algorithm which studies the operation of the installation over a random day and over a whole year. Finally, an integrated economic and environmental analysis of the proposed solution together with a comparison with the traditional operation of a GDHS was carried out. All the calculations have been done for three test cases of sizing of the geothermal part of the installation. M ore specifically, they were done for the days that their daily heat demand was the $25^{\text {th }}-, 50^{\text {th }}$ - and $75^{\text {th }}$-centile (called $25-\mathrm{C}, 50-\mathrm{C}$ and $75-\mathrm{C}$ in brief) of the daily heat demands of the whole year, respectively.

The conclusions that are drawn from this study are the following:

- The heat losses of the storage tank can be minimised if the tank is well insulated. In our case, an insulation of $20 \mathrm{~cm}$ was used and the heat losses were negligible in most of the cases.

- The importance of the heat losses in the pipelines at the initial design stage was highlighted. An optimization algorithm for their sizing that takes into account their heat losses was built. The results indicate that by using the specific algorithm, the heat losses are much smaller than other published values. This indicates that the heat losses were probably underestimated in the past and that they should be definitely taken into account on the design stage of the network. 
- B oth the capital and the operational costs are proved to be lower for the studied case compared to the traditional approach for any case of sizing.

- As the sizing of the installation increases, it was shown that the capital cost increases while the operational costs decrease.

- All the financial indices are more attractive in the proposed case compared to the traditional approach for any case of sizing. The levelised cost of heating decreases, while the NPV, the IRR and the BCR decrease.

- The highest impact of the storage occurs in the 50-C case where the heat store is utilised in an optimum way.

- On the other hand, the financial viability of the investment increases as the sizing of the installation increases. Therefore, the maximum viability occurs in the $75-\mathrm{C}$ case.

- The emissions of the installation decrease when the heat store is used since less fuel is used to cover the peak demands. The biggest absolute and relative decreases in the emissions occur in the 50-C and in the 75-C case, respectively.

- Finally, the load factor of the geothermal part of the installation increases when the heat store is applied for any case, meaning that more geothermal energy is utilised.

Therefore, it can be concluded that by applying a heat storage under the proposed control strategy in a GDHS the overall production of heat is cheaper and the peak-up boilers are used less. Increased utilisation of geothermal energy as well as substantial reduction of emissions is also succeeded with the proposed approach. All these highlight the financial and environmental benefits of this approach which are necessary for sustainable growth.

\section{ACKNOWLEDGEMENTS}

The authors would like to thank Cluff Geothermal Ltd., the Energy Technology Partnership (ETP) and the University of Glasgow for funding this research project.

\section{NOMENCLATURE}

\begin{tabular}{|c|l|c|}
\hline Symbol & Quantity & SI Unit \\
\hline \multicolumn{2}{|l|}{} \\
\hline$A$ & A rea & $\mathrm{m}^{2}$ \\
\hline$A H D$ & A nnual heat demand & $\mathrm{J}$ \\
\hline$A O H$ & A nnual operating hours & Dimensionless \\
\hline$B C R$ & Benefits-to-cost ratio & Dimensionless \\
\hline
\end{tabular}




\begin{tabular}{|c|c|c|}
\hline$C$ & Cost & $E$ \\
\hline$C C$ & Capital Cost & $E$ \\
\hline$C p$ & Specific heat capacity & $\frac{J}{k g \cdot K}$ \\
\hline$C R F$ & Cost recovery factor & Dimensionless \\
\hline$D$ & Diameter & $m$ \\
\hline$\delta h$ & Friction losses & $m$ \\
\hline$D H D$ & Daily heat demand & $k W h$ \\
\hline$d T$ & Temperature difference & $\bar{K}$ \\
\hline$d t$ & Time difference & $s$ \\
\hline$g$ & Gravitational acceleration & $\frac{m}{s^{2}}$ \\
\hline $\mathrm{H}$ & Height & $m$ \\
\hline$h$ & Convective heat transfer coefficient & $\frac{W}{m^{2} \cdot K}$ \\
\hline$I P$ & Investment period & Y ears \\
\hline$i r$ & Interest rate & Dimensionless \\
\hline$I R R$ & Internal rate of return & Dimensionless \\
\hline K & Overall heat transfer coefficient & $\frac{W}{m^{2} \cdot K}$ \\
\hline$k$ & Conductive heat transfer coefficient & $\frac{W}{m \cdot K}$ \\
\hline$L C H$ & L evelised cost of heating & $\frac{£}{k W h}$ \\
\hline$M$ & M ass & $\mathrm{kg}$ \\
\hline$\dot{m}$ & M ass flow rate & $\frac{\mathrm{kg}}{\mathrm{s}}$ \\
\hline$N P V$ & Net present value & $£$ \\
\hline $\mathrm{Nu}$ & Nusselt number & Dimensionless \\
\hline$O C$ & Operational cost & $E$ \\
\hline$\dot{P}$ & Electrical power & $W$ \\
\hline $\operatorname{Pr}$ & Prandtl number & Dimensionless \\
\hline$Q$ & Heat & Jor $k W h$ \\
\hline$\dot{Q}$ & Heat power & $W$ \\
\hline$R e$ & Reynolds number & Dimensionless \\
\hline
\end{tabular}




\begin{tabular}{|c|c|c|}
\hline$S F$ & Safety factor & Dimensionless \\
\hline$T$ & Temperature & $K$ \\
\hline$t$ & Thickness & $m$ \\
\hline$V$ & Volume & $m^{3}$ \\
\hline$\dot{V}$ & Volume flow rate & $m^{3}$ \\
\hline \multicolumn{3}{|c|}{ Greek symbols } \\
\hline$\varepsilon$ & Emissivity & Dimensionless \\
\hline$\eta$ & Efficiency & Dimensionless \\
\hline$\rho$ & Density & $\frac{\mathrm{kg}}{\mathrm{m}^{3}}$ \\
\hline$\sigma$ & Stefan-B oltzmann constant & $\frac{W}{m^{2} \cdot K^{4}}$ \\
\hline \multicolumn{3}{|c|}{ Subscripts } \\
\hline$a$ & A mbient & \\
\hline$b$ & Boiler & \\
\hline bot & Bottom part & \\
\hline$c$ & Convective & \\
\hline$c h$ & Charge & \\
\hline$c v$ & Cover & \\
\hline$D$ & Design & \\
\hline dis & Discharge & \\
\hline$d r$ & Drilling & \\
\hline el & Electrical & \\
\hline elev & Elevation & \\
\hline$f$ & Fuel & \\
\hline G & Geothermal & \\
\hline$i$ & Inner & \\
\hline in & Inlet & \\
\hline
\end{tabular}




\begin{tabular}{|c|c|c|}
\hline ins & Insulation & \\
\hline$l$ & Linear & \\
\hline loss & Losses & \\
\hline$n p$ & Network pipelines & \\
\hline$o$ & Outer & \\
\hline ot & Other & \\
\hline$p$ & Pump & \\
\hline$r$ & Radiative & \\
\hline$S$ & Substation's side & \\
\hline side & Side part & \\
\hline st & Storage & \\
\hline top & Top part & \\
\hline$t r$ & Transmission network's side & \\
\hline tot & Total & \\
\hline$u$ & Unit & \\
\hline \multicolumn{3}{|c|}{ Superscripts } \\
\hline$i$ & Time interval & \\
\hline$N$ & Last time interval & \\
\hline 0 & First time interval & \\
\hline
\end{tabular}

\section{REFERENCES}

[1] Barbier, E., Nature and technology of geothermal energy: A review. Renewable and Sustainable Energy Reviews 1, 1997, 1-69.

[2] Kecebas, A., Performance and thermo-economic assessments of geothermal district heating system: A case study in A fyon, Turkey. Renewable Energy 36, 2011, 77-83.

[3] Lund, J.W., Direct heat utilization of geothermal resources. Renewable Energy 10, 1997, 403-408.

[4] Banks, D., Thermogeology: Ground-surface heating and cooling. Wiley Blackwell, second ed., Chichester, 2012, pp.526. 
[5] Hepbasli, A., A review on energetic, exergetic and exergo-economic aspects of geothermal district heating systems (GDHSs). Energy Conversion and M anagement 51, 2010, 2041-2061.

[6] Hederman, W.F.J r., and Cohen, L.A., Economics of geothermal direct heat applications. Geothermal Resources Council Transactions 5, 1981, 647-650.

[7] Rybach, L., Geothermal energy: Sustainability and the environment. Geothermics 32, 2003, 463-470.

[8] Kecebas, A., Kayfeci, M., and Gedik, E., Performance investigation of the A fyon geothermal district heating system for building applications: Exergy analysis. A pplied Thermal Engineering 31, 2011, 1229-1237.

[9] European Geothermal Energy Council (EGEC) N ewsletter, J anuary 2015, pp.:2, last accessed on 21/07/2015.

[10] Lund, J.W., and Lienau, P.J., Geothermal district heating. In: Popovski, K., V ranovska, A., and Popovska, V.A. (eds.), Proceedings of the International Conference on National Development of Geothermal Energy Use and International Course/EGEC Business Seminar on Organization of Successful Development of a Geothermal Project, Slovakia, 2009, unpaginated.

[11] Rosada, J., Characteristics of district heating- Advantages and disadvantages. Energy and Buildings 12, 1988, 163171.

[12] Rezaie, B., and Rosen, M.A., District heating and cooling: Review on technology and potential enhancements. A pplied Energy 93, 2012, 2-10.

[13] Fang, $\mathrm{H}_{\text {., }} \mathrm{Xia}$, J., and Jiang, Y., K ey issues and solutions in a district heating system using low-grade industrial waste heat. Energy 86, 2015, 589-602.

[14] Bruckner, S., Liu, S., M iro, L., Radspieler, M., Cabeza, L.F., and Lavemann, E., Industrial waste heat recovery technologies: An economic analysis of heat transformation technologies. A pplied Energy 151, 2015, 157-167.

[15] Kanoglu, M., and Cengel, Y.A., Economic evaluation of geothermal power generation, heating and cooling. Energy $24,1999,501-509$.

[16] Ozgener, L., Hepbasli, A., Dincer, I., and Rosen, M.A., Exergoeconomic analysis of geothermal district heating systems: A case study. A pplied Thermal Engineering 27, 2007, 1303-1310.

[17] Kecebas, A., K ayfeci, M ., and Gedik, E., Performance investigation of the A fyon geothermal district heating system for building applications: Exergy analysis. A pplied Thermal Engineering 31, 2011, 1229-1237.

[18] Jie, P., Zhu, N., and Li, D., Operation optimization of existing district heating systems. A pplied Thermal Engineering $78,2015,278-288$.

[19] Y abanova, I., and Kecebas, A., Development of ANN model for geothermal district heating system and a novel PIDbased control strategy. A pplied Thermal Engineering 51, 2013, 908-916.

[20] Pagliarini, G., and Rainieri, S., M odelling of a thermal energy storage system coupled with combined heat and power generation for the heating requirements of a University Campus. A pplied Thermal Engineering 30, 2010, 1255-1261. 
[21] Kostowski, W., and Skorek, J., Thermodynamic and economic analysis of heat storage application in co-generation systems. International J ournal of Operational Research 29, 2005, 177-188.

[22] Ghaddar, N.K., Stratified storage tank influence on performance of solar water heating system tested in Beirut. Renewable Energy 4, 1994, 911-925.

[23] V erda, V., and Colella, F., Primary energy savings through thermal storage in district heating networks. Energy 36, $2011,4278-4286$

[24] Garcia-M ari, E., Gasque, M., Gutierrez-Colomer, R.P., Ibanez, F., and Gonzalez-A Itozano, P., A new inlet device that enhances thermal stratification during charging in a hot water storage tank. A pplied Thermal Engineering 61, 2013, 663-669.

[25] Haeseldonckx, D., Peeters, L., Helsen, L., and D'haeseleer, W., The impact of thermal storage on the operational behaviour of residential $\mathrm{CHP}$ facilities and the overall $\mathrm{CO}_{2}$ emissions. Renewable and Sustainable Energy Reviews 11 , 2007, 1227-1243.

[26] Campos Celador, A., Odriozola, M., and Sala, J.M., Implications of the modelling of stratified hot water storage tanks in the simulation of CHP plants. Energy Conversion and M anagement 52, 2011, 3018-3026.

[27] Kenjo, L., Inard, C., and Caccavelli, D., Experimental and numerical study of thermal stratification in a mantle tank of a solar domestic hot water system. A pplied Thermal Engineering 27, 2007, 1986-1995.

[28] Han, Y.M., Wang, R.Z., and Dai, Y.J., Thermal stratification within the water tank. Renewable and Sustainable Energy Reviews 13, 2009, 1014-1026.

[29] Jordan, U., and Furbo, S., Thermal stratification in small solar domestic storage tanks caused by draw-offs. Solar Energy $78,2005,291-300$.

[30] Bosman, M.G.C., Bakker, V., M olderink, A., Hurink, J.L., and Smit, G.J.M., Planning the production of a fleet of domestic combined heat and power generators. European J ournal of O perational Research 216, 2010, 140-151.

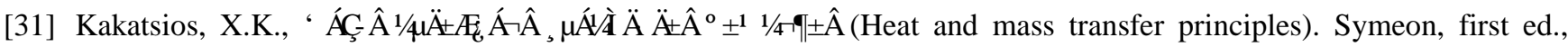
Athens, 2006, pp. 656. (in Greek)

[32] B ritish Standards Institution, 2002, European Standard: Seamless and welded steel tubes. Dimensions and masses per unit length. BS EN 10220:2002. BSI Group, London. 9pp.

[33] Bohm, B., On transient heat losses from buried district heating pipes. International J ournal of Energy Research 24, $2000,1311-1334$

[34] Krajacic, G., Duic, N., Tsikalakis, A., Zoulias, M., Caralis, Panteri, E., and Carvalho, M .D.G., Feed-in tariffs for promotion of energy storage technologies. Energy Policy 39, 2011, 1410-1425.

[35] Investopedia (http://www.investopedia.com/), last accessed on 21/07/2015.

[36] Garnish, J.; B rown, G. Geothermal energy. In Renewable Energy. Power for a Sustainable Future, 3rd ed.; B oyle, G., 
Ed.; Open University-Oxford University Press: Oxford, UK, 2012; pp. 409-459

[37] Harrison, R., Design and performance of direct heat exchange geothermal district heating schemes. Geothermics 16, $1987,197-211$.

[38] Chan, C.W., Ling-Chin, J., and Roskilly, A.P., A review of chemical heat pumps, thermodynamic cycles and thermal energy storage technologies for low grade heat utilisation. A pplied Thermal Engineering 50, 2013, 1257-1273. 